\title{
Goal-Related Activity in Hippocampal Place Cells
}

\author{
Vincent Hok, ${ }^{1 \star}$ Pierre-Pascal Lenck-Santini, ${ }^{2 \star}$ Sébastien Roux, ${ }^{3}$ Etienne Save, ${ }^{1}$ Robert U. Muller, ${ }^{4}$ and Bruno Poucet ${ }^{1}$ \\ ${ }^{1}$ Laboratory of Neurobiology and Cognition, Centre National de la Recherche Scientifique (CNRS)-Université de Provence, 13331 Marseille Cedex 03, \\ France, ${ }^{2}$ Neuroscience Center, Lebanon, New Hampshire 03756, ${ }^{3}$ Institut de Neurosciences Cognitives de la Méditerranée, CNRS-Université de la \\ Méditerranée, 13402 Marseille Cedex 20, France, and ${ }^{4}$ Department of Physiology and Pharmacology, State University of New York Downstate Medical \\ Center, Brooklyn, New York 11203
}

Place cells are hippocampal neurons whose discharge is strongly related to a rat's location in its environment. The existence of place cells has led to the proposal that they are part of an integrated neural system dedicated to spatial navigation, an idea supported by the discovery of strong relationships between place cell activity and spatial problem solving. To further understand such relationships, we examined the discharge of place cells recorded while rats solved a place navigation task. We report that, in addition to having widely distributed firing fields, place cells also discharge selectively while the hungry rat waits in an unmarked goal location to release a food pellet. Such firing is not duplicated in other locations outside the main firing field even when the rat's behavior is constrained to be extremely similar to the behavior at the goal. We therefore propose that place cells provide both a geometric representation of the current environment and a reflection of the rat's expectancy that it is located correctly at the goal. This on-line feedback about a critical aspect of navigational performance is proposed to be signaled by the synchronous activity of the large fraction of place cells active at the goal. In combination with other (prefrontal) cells that provide coarse encoding of goal location, hippocampal place cells may therefore participate in a neural network allowing the rat to plan accurate trajectories in space.

Key words: hippocampus; unit recordings; place cells; spatial processing; goal coding; rat

\section{Introduction}

Place cells are hippocampal neurons whose discharge is strongly related to a rat's location in the environment (O'Keefe and Dostrovsky, 1971). Each place cell discharges only when the animal is in a cell-specific, stable region called its "firing field," and is usually silent elsewhere in the environment. Firing fields are distributed over the whole surface of the apparatus explored by the rat (Muller, 1996) so that it is possible to reconstruct the rat's path with fair precision, knowing just the instantaneous firing for small numbers of simultaneously recorded cells (Wilson and McNaughton, 1993; Brown et al., 1998). In other words, place cells continuously signal the rat's location within its current environment. This information appears to be used by the rat during navigation performance as inducing a mismatch between the environment and the hippocampal representation of the environment disrupts the rat's behavior (O'Keefe and Speakman, 1987; Lenck-Santini et al., 2001, 2005) (but see Huxter et al., 2001; Jeffery et al., 2003).

\footnotetext{
Received March 28, 2006; revised Dec. 6, 2006; accepted Dec. 7, 2006.

This work was supported by Centre National de la Recherche Scientifique, Ministère de l'Éducation Nationale, de la Recherche, et de la Technologie (Action Concertée Incitative Neurosciences Intégratives et Computationnelles), and United States Public Health Service-National Institutes of Health Grant NS20686. We thank Boris Burle for help with the analyses, Francesca Sargolini for useful comments, and the three anonymous referees for their constructive criticisms.

*V.H. and P.P.L.-S. contributed equally to this work.

Correspondence should be addressed to Bruno Poucet, Laboratory of Neurobiology and Cognition, Centre $\mathrm{Na}$ tional de la Recherche Scientifique et Université de Provence, Centre Saint Charles, Case C, 3 Place Victor Hugo, 13331 Marseille Cedex 03, France. E-mail: bpoucet@up.univ-mrs.fr.

D01:10.1523/JNEUROSCI.2864-06.2007

Copyright $\odot 2007$ Society for Neuroscience $\quad$ 0270-6474/07/270472-11\$15.00/0
}

In recent work, place cells were recorded while rats performed a place navigation task in which they had to enter an unmarked circular goal zone in a cylindrical environment to release a food pellet from an overhead dispenser (Lenck-Santini et al., 2002). Although the main purpose was to determine how navigation performance depended on the mismatch between the environment and its hippocampal representation, an ancillary observation was that many place cells discharged a few spikes when the rat was at the goal location rather than in the primary firing field. There is currently no agreement about whether goal location significantly influences place cell activity. For example, firing fields do not tend to occur in higher numbers near goal locations (Lenck-Santini et al., 2001, 2002) and do not seem to undergo systematic changes when the goal is moved (Speakman and O’Keefe, 1990; Trullier et al., 1999; Lenck-Santini et al., 2001). In contrast, there have been several reports that firing fields occur in excess at goal locations (Gothard et al., 1996; Hollup et al., 2001; Hölscher et al., 2003; Kobayashi et al., 2003).

Given the major theoretical importance of this issue, we were interested in whether goal-related firing of place cells could be clearly documented. Accordingly, a detailed analysis of existing data (Lenck-Santini et al., 2002) was undertaken to compare discharge observed at the goal location with the discharge expected from the overall spatial firing properties of each cell. We found that place cells provide a consistent signal when the rat is at the goal. In a new, follow-up experiment, we found that sharp waves hardly ever occur at the goal in our conditions, suggesting that goal firing is not caused by the increased cell excitability associated with sharp waves. Because we saw no consistent decrease of interneuron firing at the goal, the elevated goal discharge is not 
likely attributable to global disinhibition. We therefore suggest that place cells provide rats with information about the success of navigation in addition to signaling location at the main fields.

\section{Materials and Methods}

We provide only a brief description of the general methods here because the details are given in Lenck-Santini et al. (2002). In contrast, the specific data analyses aimed at measuring place cell discharge at the goal location, detecting large irregular activity (LIA)-associated sharp waves, and assessing EEG states are fully described.

\section{Subjects}

Long-Evans black hooded male rats (R. Janvier, St.-Berthevin, France) weighing $300-350$ g were housed one per cage at $20 \pm 2^{\circ} \mathrm{C}$, under natural lighting conditions. They had free access to water and were food deprived to $85 \%$ of ad libitum body weight. All procedures complied with both U.S. and French institutional guidelines.

\section{Apparatus}

The apparatus was a gray cylinder $(76 \mathrm{~cm}$ diameter, $50 \mathrm{~cm}$ high $)$ with a plastic floor that was wiped with alcohol before each session to prevent accumulation of uncontrolled odors. The cylinder was at the center of an evenly lit area surrounded by opaque circular curtains ( $2.5 \mathrm{~m}$ diameter, $2.5 \mathrm{~m}$ high). A white card attached to the wall of the cylinder covered $100^{\circ}$ of internal arc. When activated, a food dispenser $2 \mathrm{~m}$ above the cylinder dropped $20 \mathrm{mg}$ food pellets on the apparatus floor. A radio fixed to the ceiling above the cylinder was used to mask uncontrolled directional sounds. The unit recording system and equipment for controlling the experiment were in an adjacent room.

\section{Behavioral procedures}

Behavioral training started 6 weeks before electrode implantation. After 2 weeks of daily handling, rats were trained to retrieve $20 \mathrm{mg}$ food pellets scattered on the apparatus floor (one 16 min session for $3 \mathrm{~d}$ ), at which time they readily went everywhere in the cylinder. Rats were then taught the place preference task (Rossier et al., 2000) in which they were required to enter an unmarked circumscribed zone and stay there for at least $2 \mathrm{~s}$ at which time the overhead dispenser was triggered to release a single $20 \mathrm{mg}$ pellet. The occurrence of a correct trial was recorded as the time stamp of the event. Because the pellet could go anywhere in the cylinder, the rat had to forage over the entire area to find it. A second time stamp was manually entered into the recording file at the time when the rat was observed to find the food. To trigger the release of another pellet, the rat had to spend at least $3 \mathrm{~s}$ outside the goal zone before it could be reentered. Because reward was broadly distributed over the whole cylinder, it was possible to disentangle the reward value of places from the goal value of the goal zone: any excess firing observed in the zone could not be the direct consequence of food reward because eating could occur anywhere.

To get rats to perform reliably, training was done in three steps broken into 16 min sessions. In step 1, the feeder was activated each time the rat entered an $18 \mathrm{~cm}$ radius circle. In step 2, the rat had to stay inside the goal zone for $2 \mathrm{~s}$ before a pellet was released. In step 3, the radius of the goal zone was reduced by $1 \mathrm{~cm}$ per day to a final radius of $10 \mathrm{~cm}$ (see Fig. $1 A$ ). At the completion of training, a well trained rat made approximately two correct responses per minute on average. In a second version of the task, the goal zone was directly indicated by a $10 \mathrm{~cm}$ radius black metal disc put on the cylinder floor ("cue task"), which was moved to a different location in a pseudorandom manner between sessions (Lenck-Santini et al., 2002). During all phases of training, the release zone was coextensive with the metal disk, so that across sessions no information about the drop zone location was provided by either the stimulus card or by any uncontrolled cues fixed in the environment. Training in the cue task was conducted in two steps. In step 1, the feeder was activated each time the rat visited the goal disk. In step 2, the rat was trained to stay in the disk for at least $2 \mathrm{~s}$ to release a pellet.

\section{Electrode implantation and recording methods}

At the end of training, a drivable bundle of 10 formvar-insulated $25 \mu \mathrm{m}$ nichrome electrodes (Kubie, 1984) was surgically implanted under gen- eral anesthesia (pentobarbital, $40 \mathrm{mg} / \mathrm{kg}$, i.p.). The tips of the electrode bundle were implanted above the dorsal hippocampus $(3.8 \mathrm{~mm}$ posterior, $3.0 \mathrm{~mm}$ lateral to bregma, $1.5 \mathrm{~mm}$ dorsoventral to dura) (Paxinos and Watson, 1986). Beginning 1 week after surgery, the activity from each microwire was screened daily while the rat underwent additional place preference task sessions. If no waveform of sufficient amplitude was found, the electrodes were lowered 25-50 $\mu \mathrm{m}$. A period of several hours (usually $24 \mathrm{~h}$ ) elapsed between successive screening sessions conducted in the same rat so as to guarantee electrode stability. Once a unit was isolated, it was recorded for a 16 min session. Screening and recording were done with a cable attached at one end to a commutator that allowed the rat to turn freely. The other end of the cable was connected to the rat headstage, which contained a field effect transistor amplifier for each wire, and two light-emitting diodes (LEDs) for tracking the rat's head position and direction. The signals from each electrode wire were further amplified (gain, 10,000), bandpass filtered $(0.3-10 \mathrm{kHz})$, digitized (32 $\mathrm{kHz}$ ), and stored by a Datawave Discovery system (Longmont, CO). Before a recording session, spike discharges were separated using Datawave on-line clustering software to simplify later off-line separation. The two LEDs were independently tracked with an overhead television camera connected to a digital spot follower. Each LED was detected in a grid of square regions (pixels), permitting a resolution of $6^{\circ}$ for head direction and $2.5 \mathrm{~cm}$ for head position.

\section{Data presentation and analysis}

Unit discrimination. The first step in off-line analyses was to refine boundaries for waveform clusters that were defined before recording. Candidate waveforms were discriminated using Datawave off-line sorting software, which allows waveform separation based on at most eight features. Such features usually include spike amplitude, spike duration, maximum and minimum spike voltage, and the time of occurrence of maximum and minimum spike voltages. It was also possible to discriminate according to the voltage at experimenter-defined times of the waveforms. Waveforms were then processed with Plexon (Dallas, TX) off-line sorter to refine cluster boundaries, remove outlier waveforms, and calculate sorting statistics and autocorrelation functions. Interspike interval histograms were built for each unit and the whole unit was removed from analysis if the histogram revealed the existence of interspike intervals $<2$ $\mathrm{ms}$ (refractory period), inconsistent with good isolation. Only waveforms of sufficient amplitude $(>100 \mu \mathrm{V})$ were further analyzed. Across all cells analyzed in the study (both pyramidal cells and interneurons), the mean spike height (from baseline to peak) was $200 \pm 8 \mu \mathrm{V}$ (range, $106-558 \mu \mathrm{V}$ ) yielding a mean signal-to-noise ratio $>6$ given background noise level $(\sim 30 \mu \mathrm{V})$. The mean spike amplitude (from peak to trough) of analyzed cells was $294 \pm 12 \mu \mathrm{V}$ (range, $140-688 \mu \mathrm{V}$ ). Finally, accurate unit isolation was confirmed by direct inspection of positional firing rate maps.

Analyses of spatial firing. Once single units were well separated, autoscaled color-coded firing rate maps were created to visualize firing rate distributions (Muller et al., 1987). In such maps, pixels in which no spikes occurred during the whole session are displayed as yellow. The highest firing rate is coded as purple, and intermediate rates are shown as orange, red, green, and blue pixels from low to high. A firing field was defined as a set of at least nine contiguous pixels with firing rate above grand mean rate. The location of the field centroid was calculated as in Fenton et al. (2000).

Analyses of motor correlates. Locomotion in the goal zone was unavoidably associated with low walking speeds because the task required the rat to stop for $2 \mathrm{~s}$. Thus, excess goal zone activity could occur if cell discharge were greater for slower speeds. This possibility cannot, however, be analyzed simply by determining the correlation between walking speed and cellular firing rate because spurious correlations of either sign can be obtained depending on the location of the main firing field. We therefore used a method that identified all episodes of slow walking outside the main firing field and outside the goal zone. We then compared the firing rate during such episodes to the rate at the goal location during correct responses. To extract slow-walking episodes, the rat's speed was measured for $500 \mathrm{~ms}$ intervals such that the rat spent no time in the main firing field. The sample was put in the data set if the rat's speed was inside 
the speed range seen while the rat was in the goal circle during a correct response (usually $<3 \mathrm{~cm} / \mathrm{s}$ ). The total time and the corresponding total number of spikes in slow-walking episodes were accumulated for the session duration, and the mean rate for slow-walking episodes (total number of spikes divided by the total time) was compared with the mean firing rate for slow-walking episodes during the $2 \mathrm{~s}$ goal intervals over all correct responses.

Perievent time histograms. For each place cell, comparisons were made of discharge relative to correct responses in two ways. First, raster plots of firing activity were made for the $2 \mathrm{~s}$ before the rat entered the goal zone ("before"), the required $2 \mathrm{~s}$ in the goal zone that triggered pellet release ("during"), and the $2 \mathrm{~s}$ after pellet release ("after"). Second, each of the three rasters was accumulated to produce a corresponding perievent time histogram (PETH). To obtain more reliable, system-wide estimates of activity changes, we also looked at the activity of cell ensembles. We first normalized the PETH for each cell by dividing its rate in each bin by the grand average rate. The normalized rate in each bin was then averaged across all simultaneously recorded cells.

Identification of EEG states. To examine hippocampal EEG during the $2 \mathrm{~s}$ goal period, three additional rats were trained in the place preference task using the same behavioral procedures as described (see above, Behavioral procedures). Once a criterion of $\sim 2$ correct responses per min was reached, rats were implanted with recording electrodes as described (see above, Electrode implantation and recording methods). Screening the activity from each microwire began 1 week after surgery, while rats underwent additional place preference task sessions. Once a unit or set of units was isolated, it was recorded for a 16 min session. Unit discrimination was done off-line using the methods described (see above, Unit discrimination). Along with unit data, hippocampal CA1 pyramidal EEG (filtered between 0.1 and $500 \mathrm{~Hz}$ ) was simultaneously recorded from two electrodes. Two methods were used to identify sharp waves. Because they are associated with ripples (transient $100-400 \mathrm{~Hz}$ events), we first looked for evidence of high-frequency events by calculating EEG power spectral densities (PSDs) for both the whole 16 min session and for the pooled $2 \mathrm{~s}$ bouts associated with correct responses. Fast Fourier transforms were computed using Hann windowing and PSDs analyzed in more detail in the ripple band $(100-200 \mathrm{~Hz})$. PSD slopes in the ripple band range were always negative indicating reduced power with increasing frequency. To examine high-frequency power during correct responses relative to the whole session, we compared PSD slopes for the two period types. A second analysis examined the possible occurrence of ripples on a trialby-trial basis. We first filtered the EEG in the ripple band during each $2 \mathrm{~s}$ goal period and computed an average trace across all trials of a session. We then asked if each trial-specific trace crossed a threshold 5 SDs above the averaged trace. In cases in which the threshold was exceeded, the occurrence of a ripple was confirmed or rejected by visual inspection of the original trace. A similar analysis was done around the time at which a rat found food after a correct response.

To quantify theta activity, we calculated mean EEG power and peak frequency in the $4-12 \mathrm{~Hz}$ theta band separately for the $2 \mathrm{~s}$ preceding goal arrival and the $2 \mathrm{~s}$ goal period. We also conducted a more detailed analysis of possible changes of mean event-related power [event-related spectra perturbations (ERSPs)] in the theta band for the same periods using EEGLAB (Delorme and Makeig, 2004). Briefly, the baseline spectrum was calculated for the $2 \mathrm{~s}$ period before each goal arrival. Calculating the ERSP requires computing the power spectrum over a sliding latency window (using wavelet analysis; cycles, 3). Baseline-normalized response transforms for all trials within a session were then averaged to produce an average ERSP (Makeig, 1993). Significance of deviations from baseline power during $2 \mathrm{~s}$ goal periods (indicating significant changes in EEG state) was assessed using a bootstrap method $(p<0.01)$.

\section{Results}

\section{General observations}

Data were initially obtained from five rats trained on the place preference task. Each rat performed the place preference task reliably during a total of 37 recording sessions. On average, rats made $32.4 \pm 1.0$ correct responses per $16 \mathrm{~min}$ session, a level similar to previous reports (Rossier et al., 2000; Hok et al., 2005). Furthermore, the number of correct entries into the goal zone $(2.03 \pm 0.06$ entries $/ \mathrm{min})$ was much greater than into a symmetrically located control zone in the opposite quadrant $(0.2 \pm 0.03$ entries/min; $\left.t_{(36)}=13.2 ; p \ll 0.0001\right)$. Direct observation of rats' behavior during correct pauses at the goal zone revealed that they were simply staying still and not displaying any consistent overt behavior. Thus, correct responses were not associated with rearing or other characteristic behaviors such as circling or headelevated posture. Correct trials were always followed by a foraging episode during which the rat explored the arena to find the released food pellet. Once food had been found and eaten, rats usually returned immediately to the goal zone to trigger another pellet release. Thus, the task required the rat to make targetdirected movements to the unmarked goal while preserving the undirected foraging behavior necessary for sampling place cell activity everywhere in the apparatus.

\section{Spatial analysis of pyramidal cell firing}

We analyzed the activity of 174 pyramidal (complex-spike) cells recorded during the 37 sessions for an average of 4.7 cells per session. Of the total sample, 22 cells were "silent"; they discharged only a few spikes in a session and did not have a firing field according to our criteria. The sporadic firing of these silent cells often appeared to be concentrated in the target zone, but their properties were not further characterized.

The remaining 152 cells were place cells with clear spatially selective firing. Their fields were well delimited and stable within a recording session. We determined the spatial firing field distribution of the main 152 cell sample by calculating the centroid of the positional firing pattern of each cell. The plot of centroid locations on a diagram of the apparatus (Fig. $1 B$ ) suggests that firing fields were widely distributed in the cylinder, although they were more numerous at the edge of the apparatus than in the center (Wiener et al., 1989). When each field centroid was assigned to one of six equally sized sectors, the number of fields in each was not different from a random distribution $\left(\chi^{2}=1.48\right.$; $\mathrm{dl}=5$; NS) so that their radial distribution did not overrepresent the goal sector.

The spatial firing distributions of 12 example cells whose fields did not encroach on the goal zone are shown in Figure 1C. Each example illustrates the basic phenomenon reported here, namely that place cells often fire what appears to be an excess number of spikes in the vicinity of the goal location in addition to their characteristic firing field. For some cells, this excess appeared as a distinct, "secondary" field in firing rate maps. Clear examples of goal-related firing were seen for both very well isolated cells (with the largest spikes) and cells with smaller spikes (values given in Fig. 1). Of the 152 cells, the main field of 71 encroached on the goal zone to an extent that a separate goal field could not be distinguished. Based on visual inspection of the firing rate maps of the remaining 81 cells, we found that 68 (84\%) had a clear secondary active region firing in the goal zone. For these 68 cells, out-of-field firing in the goal zone was significantly greater than elsewhere in the apparatus $[0.42 \pm 0.2$ vs $0.27 \pm 0.01$ action potential $\left.(\mathrm{AP}) / \mathrm{s} ; t_{(67)}=5.14 ; p \ll 0.0001\right]$. We also compared out-of-field firing in the goal zone and in an equal area control zone at a different place in the apparatus an equal distance from the wall. When all cells whose fields did not encroach on the goal zone were considered $(n=81)$, the out-of-field firing in the goal zone $(0.39 \pm 0.02 \mathrm{AP} / \mathrm{s})$ was well above out-of-field firing $(0.19 \pm$ $0.02 \mathrm{AP} / \mathrm{s})$ in the control zone comparison $\left(t_{(80)}=5.99 ; p \ll\right.$ $0.0001)$. 
(A) Behavioral task

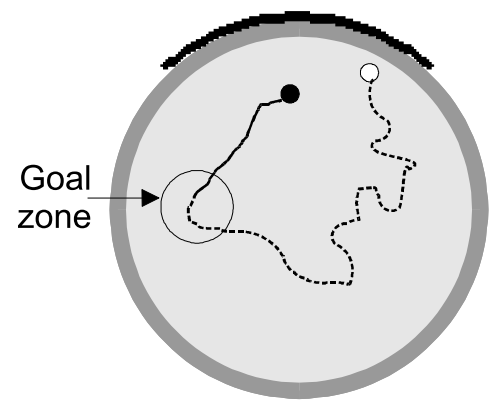

(B) Distribution of field centroids

\section{(C) Representative firing rate maps}
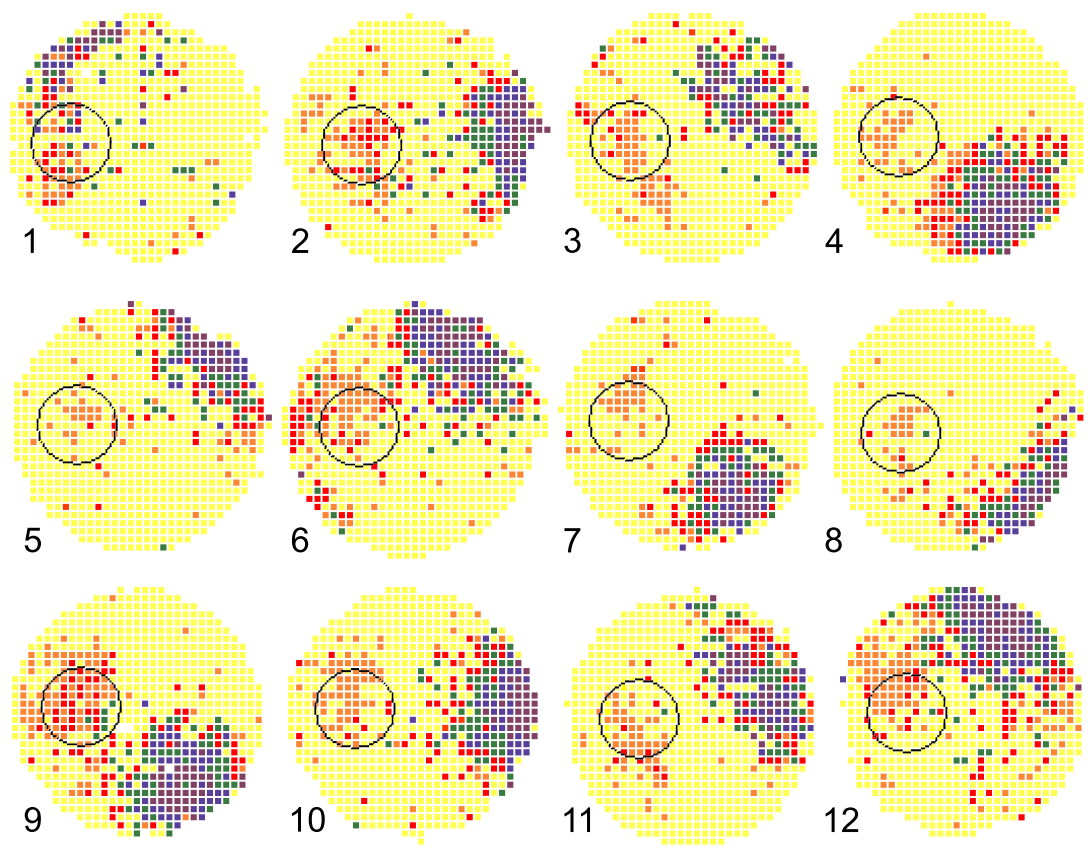

\section{(D) Decomposition of a firing rate map into behavioral episodes}

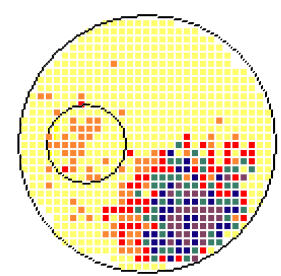

Whole session

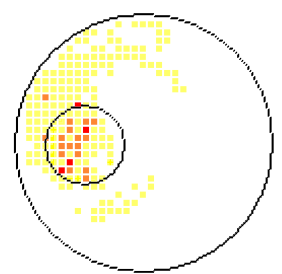

Navigation

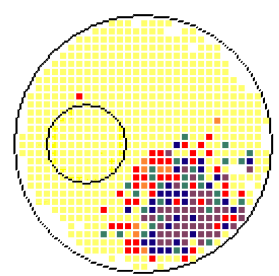

Foraging
Figure 1. A, Sketch of the place preference task. The rat must enter an unmarked goal zone to release a food pellet from an overhead feeder. To find and eat a food pellet, the rat has to forage around the cylinder. The black dot shows the start of a navigational path originating perhaps at the location where a previously released food pellet was found. The solid line shows the path taken to the goal zone (black circle) where the rat must stay for $2 \mathrm{~s}$ to release a pellet. The dashed line shows the foraging path taken after pellet release; it ends at the white dot where the rat finds the pellet. $\boldsymbol{B}$, Distribution of the centroids of place cell firing fields in the cylinder. The goal zone is shown as a gray disk. $\boldsymbol{C}$, Firing rate maps for 12 example place cells with putative excess discharge in the goal zone. Each firing rate map was generated using data from the entire recording session. In all maps, yellow indicates no firing and purple indicates maximum firing (orange, red, green, and blue indicate intermediate firing rates from low to high). Median firing rates for purple pixels and mean spike amplitudes are as follows: cell 1, $10.3 \mathrm{AP} / \mathrm{s}(196 \mu \mathrm{V})$; cell 2, $16.3 \mathrm{AP} / \mathrm{s}$ (154 $\mu \mathrm{V})$; cell 3, $6.0 \mathrm{AP} / \mathrm{s}(242 \mu \mathrm{V})$; cell 4, $12.8 \mathrm{AP} / \mathrm{s}(162 \mu \mathrm{V})$; cell 5, $13.3 \mathrm{AP} / \mathrm{s}(242 \mu \mathrm{V})$; cell 6, $14.7 \mathrm{AP} / \mathrm{s}$ (185 $\mu \mathrm{V})$; cell 7, 39.1 AP/s $(546 \mu \mathrm{V})$; cell 8, $20.4 \mathrm{AP} / \mathrm{s}(569 \mu \mathrm{V})$; cell 9, $22.5 \mathrm{AP} / \mathrm{s}(150 \mu \mathrm{V})$; cell 10, $30.3 \mathrm{AP} / \mathrm{s}(162 \mu \mathrm{V})$; cell 11, $13.7 \mathrm{AP} / \mathrm{s}(173 \mu \mathrm{V})$; cell $12,21.9 \mathrm{AP} / \mathrm{s}(212 \mu \mathrm{V})$. $\boldsymbol{D}$, Firing rate map for an entire session of a place cell (left) separated into navigation episodes (middle) and foraging episodes (right). Navigation maps for a session were based on accumulated 4 s intervals from before pellet release; these included $2 \mathrm{~s}$ of navigation to the zone and $2 \mathrm{~s}$ in the zone. Foraging maps were constructed from remaining data samples of the same session. Median firing rates for purple pixels were $12.8 \mathrm{AP} / \mathrm{s}$.
Is this excess goal firing specific to performance of the task or does it happen also during foraging in the cylinder? To address this issue, we analyzed cell discharge during "navigation" and "foraging" episodes for cells whose fields did not encroach on the goal zone. A navigation episode was defined as the $4 \mathrm{~s}$ period that immediately preceded a correct response and that ended with a reward being released by the food dispenser. The rat was otherwise considered to be foraging, with the additional constraint that its speed (measured over $500 \mathrm{~ms}$ intervals) was above the mean speed during that session, guaranteeing that it was not attempting unsuccessfully to get a pellet. Visual inspection of firing rate maps for the two episode types (Fig. $1 D)$ revealed that excess firing was seen only during navigation episodes for 66 of the 68 cells (97\%) whose primary field was well away from the goal zone.

\section{Behavioral analyses of goal-related place cell firing}

A difficulty with the preceding analysis is that rats learned to stay in the goal zone continuously for $2 \mathrm{~s}$ to release a reward so that the excess discharge was unavoidably associated with slow walking or immobility. We examined this possibility by comparing cell activity during successful slowwalking episodes in the goal zone to slowwalking episodes elsewhere in the apparatus but not in the main firing field of the cell (see Materials and Methods). We found that slow-walking discharge was significantly greater at the goal zone than elsewhere. This was true if all 152 cells were included $(1.35 \pm 0.13$ vs $0.56 \pm 0.05 \mathrm{AP} / \mathrm{s}$; $\left.t_{(151)}=7.66 ; p \ll 0.0001\right)$ and also after including only the 81 cells whose field was away from the goal zone $(0.82 \pm 0.08$ vs $0.42 \pm 0.04 \mathrm{AP} / \mathrm{s} ; t_{(80)}=5.21 ; p \ll$ 0.0001 ).

A difficulty in measuring speed over a $500 \mathrm{~ms}$ interval is that it is not exactly matched to the duration of pauses at the goal. We therefore calculated running speed during nongoal intervals of 1 or $2 \mathrm{~s}$, although such intervals were relatively rare. We found that rates for pauses away from the goal zone of 1 or $2 \mathrm{~s}$ were invariably lower than for equal duration pauses in the goal zone. Numerically, the 81 cells with fields away from the goal zone fired more in the goal zone $(0.82 \pm 0.08 \mathrm{AP} / \mathrm{s})$ than in nongoal locations during both $1 \mathrm{~s}$ $\left(0.46 \pm 0.04 \mathrm{AP} / \mathrm{s} ; t_{(80)}=4.53 ; p \ll\right.$ $0.0001 ; n=23$ samples per session on average) and $2 \mathrm{~s}$ pauses $(0.42 \pm 0.04 \mathrm{AP} / \mathrm{s}$; $t_{(80)}=4.66 ; p \ll 0.0001 ; n=7$ samples per session on average). In short, increased 
(A)

(B)

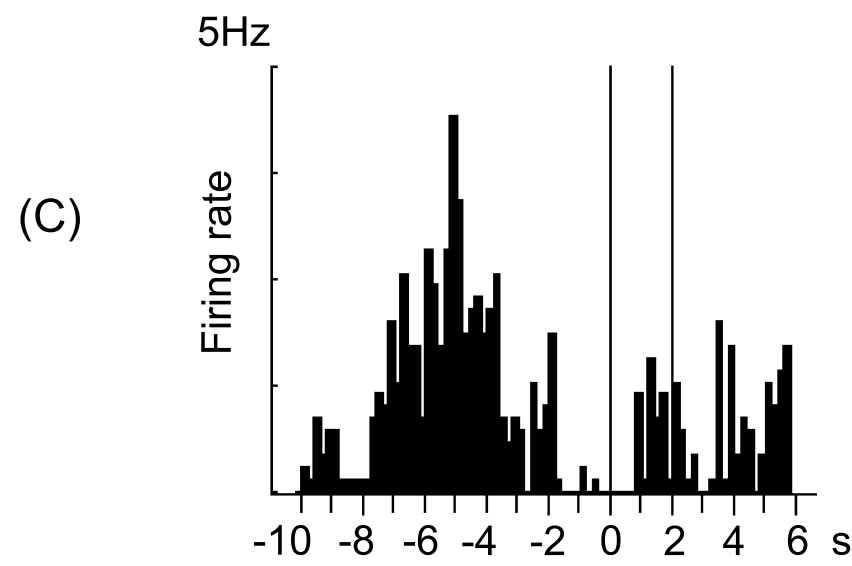

Figure 2. Characterization of the spatial and temporal activity of an exemplar place cell. $A$, Firing rate map. The main firing field occupied an arc of $\sim 70^{\circ}$ from 3:30 to 5:30 $o^{\prime}$ clock. There was also a distinct, secondary firing region at the goal. $\boldsymbol{B}$, Raster plot. Each row shows $16 \mathrm{~s}$ of data for a "trial" and is aligned to the release of a food pellet at $t=2 \mathrm{~s}$. Each trial starts $10 \mathrm{~s}$ before entry into the goal zone, continues for the $2 \mathrm{~s}$ goal period and then for $4 \mathrm{~s}$ after food release. The tick marks along a row indicate the time of an action potential. The vertical lines (continued in $\mathrm{C}$ ) show the $2 \mathrm{~s}$ goal period. The intense activity bursts in some pregoal periods occur because the rat happens to navigate toward the goal zone on a path that goes through the main firing field. C, Perievent histogram. The timescale is the same as for the raster plot. Action potential activity is accumulated across trials in $200 \mathrm{~ms}$ bins. The activity peak in the range from -7 to $-3 \mathrm{~s}$ reflects the tendency of this rat to go through the main firing field of the cell with the indicated lag before entering the goal zone.

firing at the goal location during correct responses is not attributable to prolonged stationary behavior because equivalent behavior elsewhere was not accompanied by increased firing.

\section{Temporal structure of goal-related firing}

How does discharge vary once a rat enters the goal zone? To address this issue we made raster plots and PETHs of activity for each cell using feeder operation at the end of a successful $2 \mathrm{~s}$ period stay in the goal zone as the alignment event. In raster plots and PETHs, $t=0 \mathrm{~s}$ is when the rat entered the goal zone and $t=$ $2 \mathrm{~s}$ is when the dispenser was activated. Because preliminary analysis of $16 \mathrm{~s}$ intervals starting $10 \mathrm{~s}$ before goal zone entry and terminating $4 \mathrm{~s}$ after pellet delivery revealed frequent confounding visits to the main firing field location (Fig. 2), analysis was confined to $6 \mathrm{~s}$ intervals starting at $t=-2 \mathrm{~s}$ and ending at $4 \mathrm{~s}$; no attempt was made to eliminate paths that took the rat through the main firing field before or after dwell in the goal zone.

This temporal analysis revealed several interesting findings. First, as expected, the delay period was associated with a clear increase in cell firing for the great majority of cells. For some cells (Fig. 3, cells D, G, O), the increases were unreliable from trial to trial but other cells (Fig. 3, cells C, L, N) showed consistent firing activity across most, if not all, trials. Second, in many cases, goal zone discharge did not begin when the rat entered the zone but rather was delayed by a few hundred milliseconds (Fig. 3, cells B, $\mathrm{D}, \mathrm{J}, \mathrm{M})$. Third, goal discharge often decreased at the end of the $2 \mathrm{~s}$ goal period (Fig. 3, cells D, I, J). Finally, a response in many neurons was evoked by food dispenser activation (Fig. 3, cells F, G, L).

To further characterize the temporal properties of goalrelated discharge, we made a cumulative PETH for all trials from all cells after normalizing the activity of each cell separately (Fig. 4A) (see Materials and Methods). As expected from the examples of Figure 3, the average pattern seen in Figure 4 is a gradual activity increase that peaks $\sim 1-1.2 \mathrm{~s}$ after goal zone entry and has a second peak just after reward time (2s).

This pattern of rate change was confirmed by a nonparametric analysis that determined the first moment at which the smoothed PETH for each cell exceeded the half-height of the peak of the PETH (Gawne et al., 1996; Friedman and Priebe, 1998). As shown in Figure $4 B$, the modal time of rate increase was during the second half of the delay period.

Is the tendency of firing rate to increase after a second in the goal zone attributable to a detectable behavior shift? A comparison of mean walking speed during the first and second halves of the $2 \mathrm{~s}$ goal interval failed to reveal a significant difference (first second, $2.92 \pm 0.33 \mathrm{~cm} / \mathrm{s}$; second second, $2.75 \pm 0.28 \mathrm{~cm} / \mathrm{s} ; t_{(36)}$ $=1.03$; NS). Dividing the goal interval into $500 \mathrm{~ms}$ segments did not change the conclusion $\left(F_{(3,108)}=1.06 ; p=0.37\right.$; NS $)$. We conclude that the delay of rate increase after entering the goal zone is unlikely attributable to changes in walking behavior.

\section{Comparison of goal-related firing in place and cue tasks}

The importance of the delayed goal zone rate increase in the hidden goal task is made clear by comparison with goal zone activity in a related "cue" task. In the cue task, the goal zone was made apparent by the location of a black metal disk on the cylinder floor that was moved in a pseudorandom manner between sessions (Lenck-Santini et al., 2002). In the cue task, the rat had to spend $2 \mathrm{~s}$ with its head above the disk to release a pellet. Of 87 place cells recorded from five rats performing the cue task, 34 had clear out-of-field firing at the goal location as seen from firing rate maps. A cumulative PETH for all cue-task trials from all cells revealed that peak activity occurred as soon as the rat reached the goal zone (Fig. 5A). An analysis of the timing of activity changes relative to the smoothed perievent histogram of each cell (see above) showed that the change tended to occur when the rat arrived at the goal zone, although the distribution of peak rate increase in the goal zone was rather flatly distributed (Fig. 5B). A $\chi^{2}$ test showed that the distributions of peak rate increase were reliably different for the cue and place navigation tasks $\left(\chi^{2}=\right.$ $17.2 ; \mathrm{df}=5 ; p<0.005)$. Moreover, this difference could not be explained by differences in the rats' speed profiles, which were similar in the two tasks. For each animal, the mean speed was calculated over $500 \mathrm{~ms}$ intervals starting $1 \mathrm{~s}$ before and ending $2 \mathrm{~s}$ after the rat reached the goal zone (Fig. 5C). An ANOVA for these data revealed no effect of task $\left(F_{(1,8)}=1.23\right.$; NS). There also was 

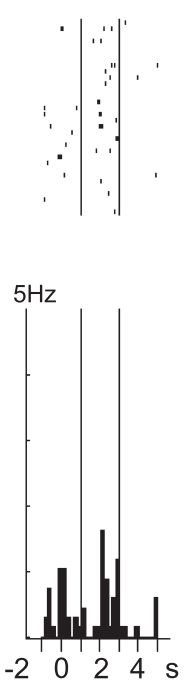

(A)
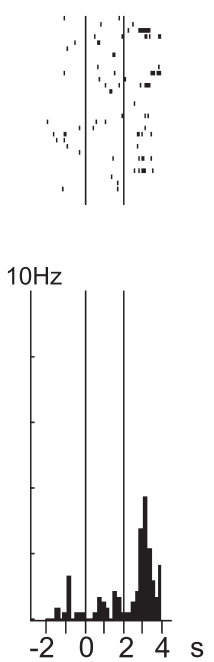

(F)

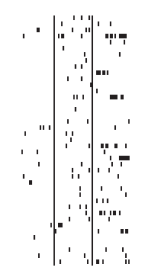

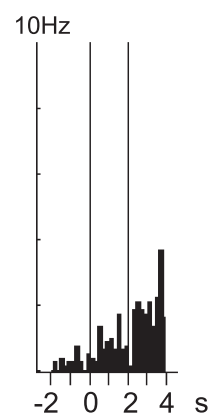

(K)

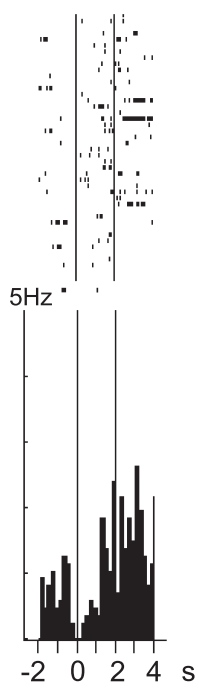

(B)
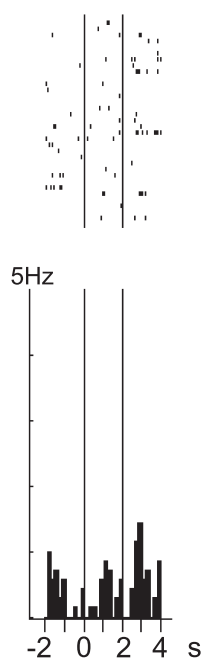

(G)
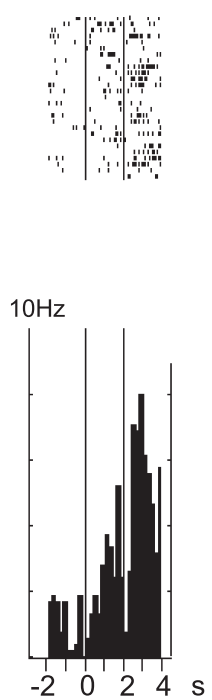

$(\mathrm{L})$
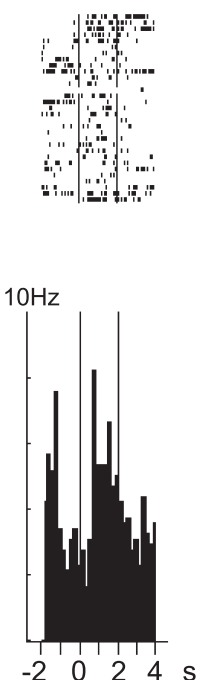

(C)
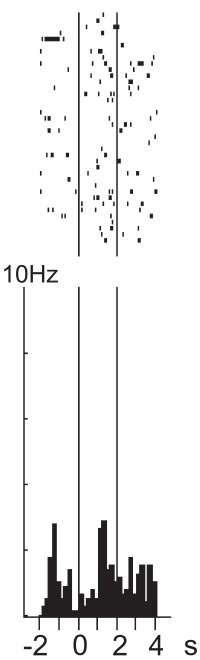

(H)
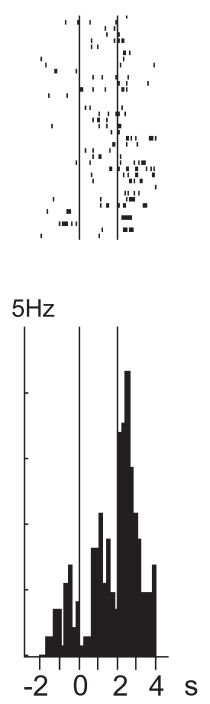

(M)

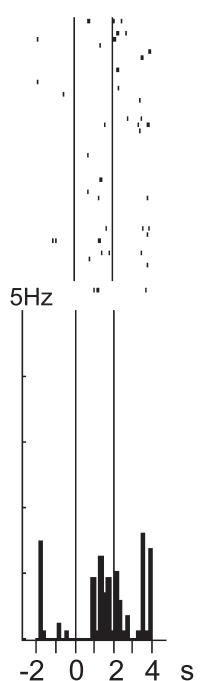

(D)
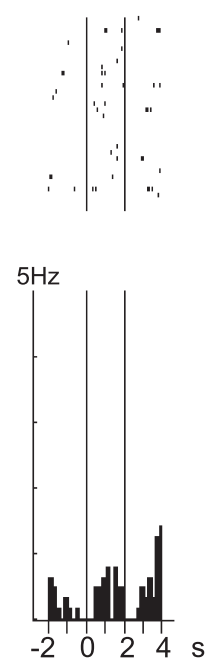

(I)
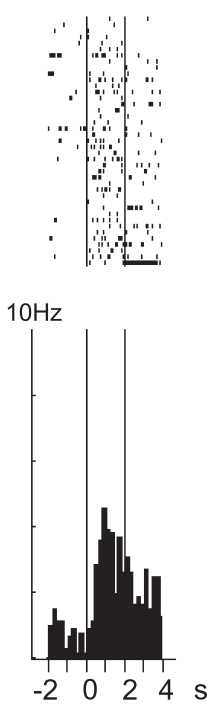

(N)
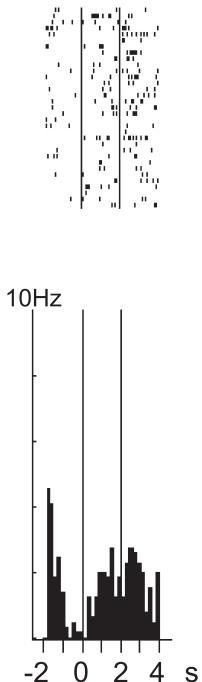

(E)
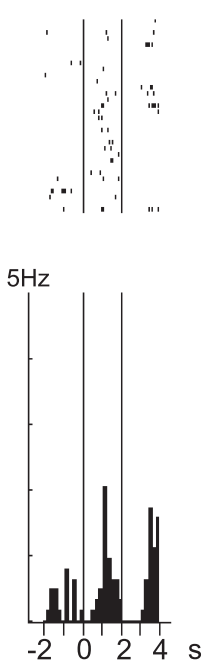

(J)
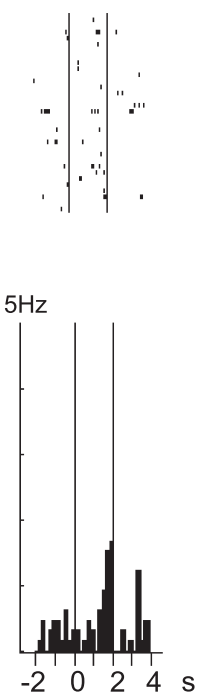

(O)
Figure 3. Temporal activity of 15 example place cells. Raster plots and PETHs for 15 place cells. In raster plots, each row summarizes a successful pause in the goal zone trial; small ticks indicate the time of an action potential. The left vertical line is the time when the rat entered the goal zone and the right vertical line shows the end of the $2 \mathrm{~s}$ release period. Perievent histograms show activity accumulated across trials on the same timescale as the corresponding raster plot. (Figure legend continues.) no interaction between speed and task $\left(F_{(5,40)}=1.31\right.$; NS $)$. We also note that a high-resolution analysis of speed as a function of time showed abrupt slowing (ranging from -31 to $-75 \%) 20$ ms before the rat entered the goal zone in both tasks and for all rats (data not shown).

\section{Analysis of coincident firing in} simultaneously recorded place cells Are the observed rate increases during the 2 s delay period synchronous, although no specific sensory event occurs during this interval? To assess this possibility, we calculated the cross-correlation for cell pairs at $5.0 \mathrm{~ms}$ resolution starting $2 \mathrm{~s}$ before goal zone entry stopping at the end of the $2 \mathrm{~s}$ delay period; the $2 \mathrm{~s}$ period after pellet release was not used because the sound of food dispenser activation evoked an immediate response from many cells as expected from the known sensory sensitivity of hippocampal neurons (Sakurai, 1990, 2002). To be included in the analysis, simultaneously recorded place cells had to have the following: (1) elevated goalrelated firing and (2) spatially separate firing fields neither of which encroached on the goal zone. The second criterion guaranteed that coactivity could not result from the great activity in firing fields. Figure 6 is a color-coded visualization of the time relationship of firing for one neuron pair confined to the $2000 \mathrm{~ms}$ delay period. The time lag between spikes in the two cells is plotted on the $y$-axis and the magnitude of the spike coincidence is shown as color. For this pair, coincidental firing began $\sim 900$ ms after the goal zone entry and persisted for $\sim 400 \mathrm{~ms}$. High coincidence was restricted to lags of approximately \pm 10 $\mathrm{ms}$, indicating that synchronization occurs only over short intervals.

The conditions for coincidence analysis stated above were met in two of five rats from which we obtained 90 cell pairs (rat 1 , 69 neuron pairs during eight sessions for a total of 2253 trials in which spike coincidence was analyzed in pairs of neurons; rat 2,21 neuron pairs, eight sessions for a total of 682 analyzed trials). In both rats, we found a highly significant increase of coincident spikes during the delay period (on average, $1.63 \pm 0.39$ per session) compared with the predelay period $(0.71 \pm$ $0.25 ; t_{(89)}=3.64 ; p<0.0005 ;$ rat $1, t_{(68)}=$ $3.0, p<0.002$; rat $2, t_{(20)}=2.06, p<0.03$; paired tests). We note that this coincidence analysis of place cell pairs only broadly characterizes relative timing because of two properties of goal zone discharge. First, cells in the sample had a very low average discharge rate $(0.598 \pm 0.069$ 
(A)

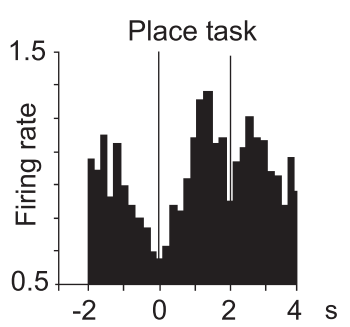

(B)

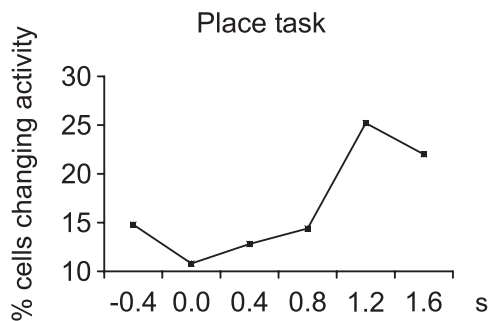

Figure 4. Characteristics of population activity during the goal period. A, Cumulative PETH for all place cells recorded from rats tested in the place task $(n=152)$. The $2 \mathrm{~s}$ goal period $(0-2$ s) is bracketed by vertical lines ( $200 \mathrm{~ms}$ bins). The activity of each cell was normalized before summation was done over the sample. Note that the mean peak activity is delayed $\sim 1 \mathrm{sinto}$ the goal period. $\boldsymbol{B}$, Percentage of cells whose activity showed the greatest increase at different times during the goal period of the place task. Entry into the goal zone is at $t=0 \mathrm{~s}$. The delay suggested in the average of the cumulative PETH is seen here as a sharp rise near the middle of the goal period.

$\mathrm{AP} / \mathrm{s} ; n=62$ cells). Second, feeder activation occurred after the interval during which synchronization was detected so that there was no sensory signal either before or during the $2 \mathrm{~s}$ goal period allowing time-locked activity on a trial basis. These features may cause considerable intertrial variability so that spike synchronization by the current definition occurred during only in a small fraction (14.6\%) of trials. Nevertheless, the elevated coincidence during the delay period suggests that the increased discharge of single pyramidal cells may be associated with elevated networkwide excitability.

\section{Relationship between goal-related place cell firing and EEG states}

A possible explanation of goal excess activity is that it occurs during sharp waves/ripples (SWRs) that reflect increased hippocampal excitability (Buzsáki, 1986). SWRs are usually associated with LIA during quiet alertness, although they also may be observed during exploratory behavior (O'Neill et al., 2006). To explore this hypothesis, we examined the hippocampal EEG along with unit activity in three additional rats well trained in the place preference task. These rats made an average of $1.8 \pm 0.1$ correct responses per minute in 17 recording sessions, a performance level equal to the other rats $(p>0.05)$ and well above the number of $2 \mathrm{~s}$ dwells in the opposite control zone $\left(0.4 \pm 0.1 ; t_{(16)}\right.$ $=6.41 ; p<0.0001)$. Place cells recorded from the second set of rats had well delimited, stable firing fields and displayed clear firing increases at the goal zone. In agreement with the initial results, the cumulative PETH for all place cells recorded from the second set of rats revealed increase goal zone firing after a delay of $\sim 1 \mathrm{~s}$ (Fig. 7A). Thus, the two sets of rats appeared identical in regard to behavior and place cell properties.

To identify sharp waves, we analyzed high-frequency events for whole $16 \mathrm{~min}$ sessions and for pooled $2 \mathrm{~s}$ periods before correct responses (see Materials and Methods, Identification of EEG states). We found that PSD negative slopes were consistently

\section{$\leftarrow$}

(Figure legend continued.) Although none of the firing fields of the 15 place cells was in the goal zone, most showed a marked increase of discharge during the goal period. Increases outside the 2 s goal period could have several causes. Usually, such increases occur because the rat traversed the main firing field of the cell on some trials before or after a correct visit to the goal. For example, the raster plot of cell J suggests field traversals after correct responses for previous trials but before correct responses in the final trials of the session. Some cells also responded to the auditory stimulus associated with activation of the food dispenser at $t=2 \mathrm{~s}$ (e.g., cell M).
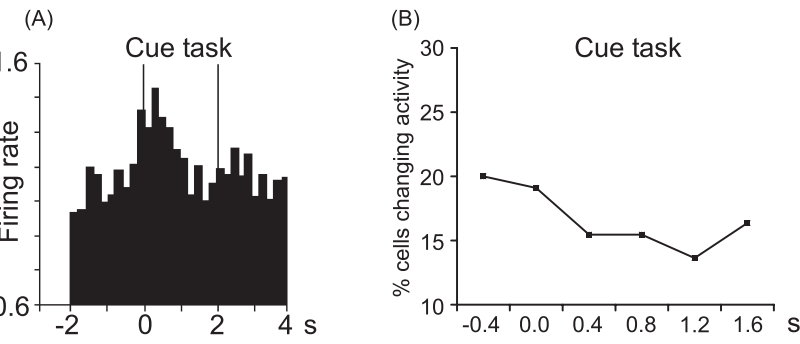

(C)

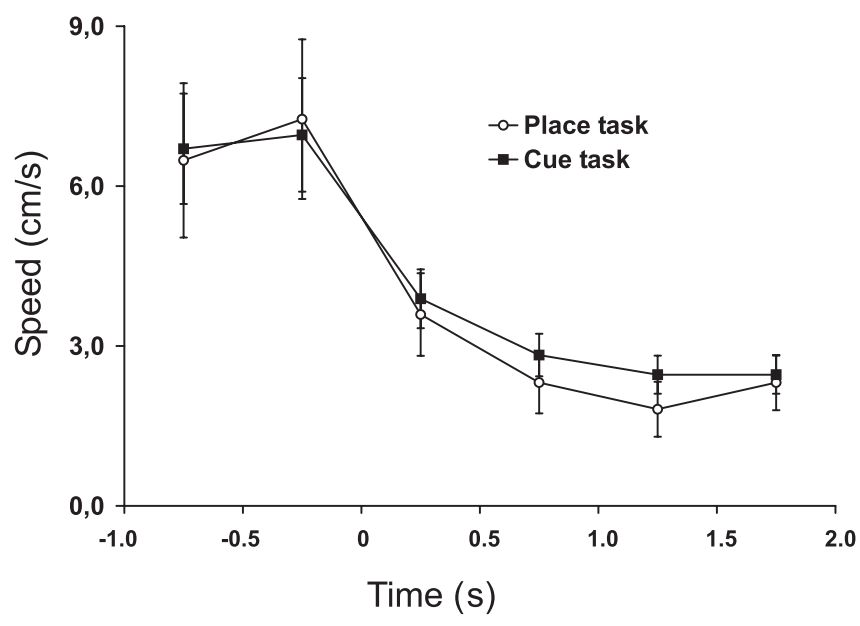

Figure 5. A, Cumulative normalized PETH for all place cells in the cue task $(n=87)$. The $2 \mathrm{~s}$ goal period $(0-2 \mathrm{~s})$ is bracketed by vertical lines ( $200 \mathrm{~ms}$ bins). In contrast to the delayed peak for the hidden goal place task, the histogram for the visible goal cue task shows a peak just after the rat's entry into the goal zone. $\boldsymbol{B}$, Percentage of cells increasing their activity at different times during the goal period of the cue task. The profile is in great contrast to the equivalent for the hidden goal task shown in Figure 4B. C, Comparison of speed profiles in the hidden and visible goal tasks at $0.5 \mathrm{~s}$ resolution starting $1 \mathrm{~s}$ before the goal period and continuing to its end. Goal zone entry is at $t=0 \mathrm{~s}$. Several behavioral features are visible including a marked slowing of running speed just after goal zone entry, quite similar speeds in the first and second halves of the goal period, and a near identity of the profiles for the two tasks. Error bars indicate SEM.

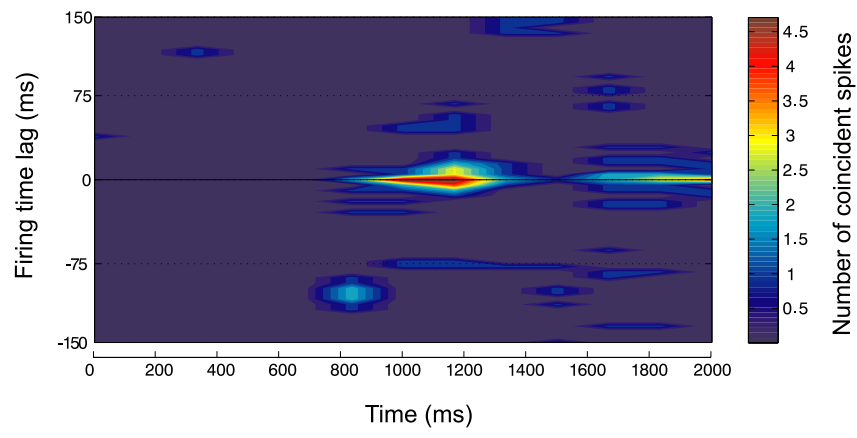

Figure 6. A cross-correlogram showing the number of coincident spikes between two cells during the $2000 \mathrm{~ms}$ goal period. The correlogram was made using sliding windows $(300 \mathrm{~ms}$ with a time shift of $150 \mathrm{~ms}$; bin width, $5 \mathrm{~ms}$ ). The time lag between spikes in the two cells is plotted on the $y$-axis, and the magnitude of spike coincidence is shown as indicated by the color scale on the right. An increase in synchronized discharges was observed $\sim 1000-1200 \mathrm{~ms}$ after the rat entered the goal zone.

steeper (by $\sim 20 \%$ ) for pooled $2 \mathrm{~s}$ goal dwells than for the whole session, indicating reduced power in the $100-200 \mathrm{~Hz}$ range during correct responses compared with the whole session $\left(-0.0218 \pm 0.0018 \mathrm{vs}-0.0178 \pm 0.0013 ; t_{(16)}=4.28 ; p<0.001\right)$. We also made a trial-by-trial inspection of filtered $(100-200 \mathrm{~Hz})$ 
(A)

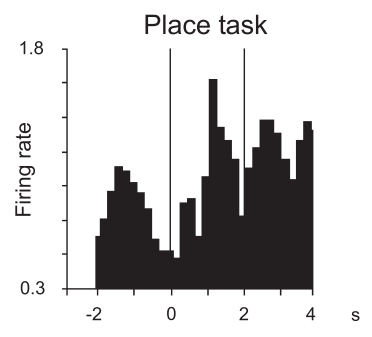

(B)
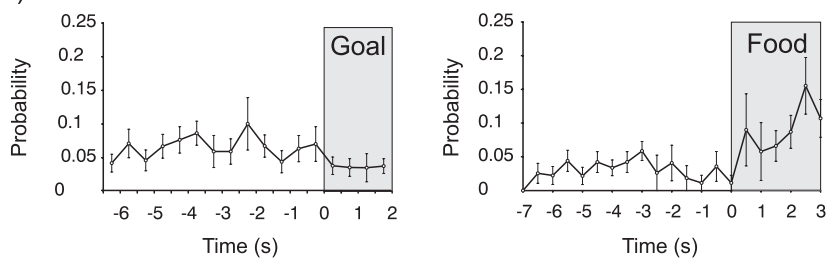

(C)

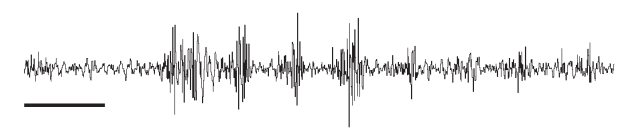

(D)

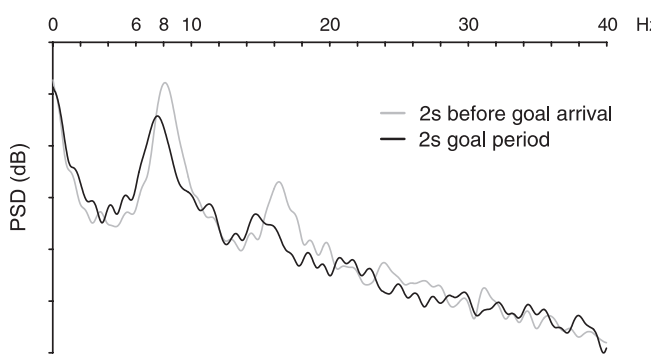

(E)

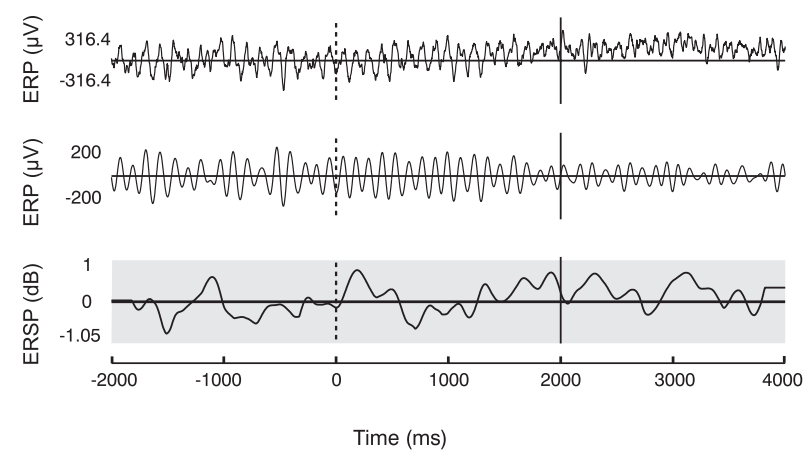

Figure 7. $A$, Cumulative normalized PETH for all place cells $(n=27)$ recorded from the second batch of rats tested in the place task. The $2 \mathrm{~s}$ goal period $(0-2 \mathrm{~s})$ is bracketed by vertical lines ( $200 \mathrm{~ms}$ bins). The histogram shows a peak at the middle of the goal period and has the same appearance as the first place cell sample (Fig. 4A). B, Left, Relative distribution of the occurrence of SWRs before and during the goal period. Rat's entry in the goal zone is at $t=0$. The overall mean occurrence rate of SWRs was low $\left(0.23 \mathrm{~s}^{-1}\right)$, and there was a tendency for ripples to occur at an even lower rate during the $2 \mathrm{~s}$ goal period (shown on gray background). Right, Relative distribution of SWRs before and after food finding; there is a clear increase in the occurrence of SWRs after food finding. Food finding is at $t=0$. C, Filtered hippocampal EEG showing SWRs after food finding; such striking events would have been easily detected during goal waiting periods. Calibration, $200 \mathrm{~ms}$. D, Representative examples of the PSD during the $2 \mathrm{~s}$ period preceding arrival to the goal zone before a correct response (black line) and during the subsequent 2 s goal period (gray line). The PSDs reveal the existence of a peak in the theta band during both epochs. A downward shift of peak power frequency was observed during the goal periods of all recorded sessions, suggesting a switch from type I to type II theta. $\boldsymbol{E}$, Dynamic analysis of changes in theta activity. In this representative example, the top trace is the average unfiltered EEG during one session made up of 32 trials. The middle trace shows average filtered EEG $(4-12 \mathrm{~Hz})$. The bottom trace shows the time course of event-related power perturbations. Shaded areas show nonsignificant values $(p>0.01)$.
EEG during each $2 \mathrm{~s}$ goal period and compared it with the averaged trace across all trials of a session (Lee and Wilson, 2002; Foster and Wilson, 2006). In none of the 360 correct trials (17 recording sessions) did we observe an increased SWR occurrence. To address this issue numerically, we plotted the time of observed ripples relative to the time of entries into the goal zone and to the time of food finding (see Materials and Methods). We saw no increase of SWRs after entry into the goal zone (Fig. 7B, left); if anything, the incidence of SWRs decreased during dwell in the goal zone, although the decrease from the preceding $2 \mathrm{~s}$ interval only approached reliability $\left(t_{(16)}=1.60\right.$; NS). In contrast, SWR occurrence increased reliably immediately after food finding (during eating) relative to the immediately preceding period $(p<0.05)$ (Fig. $7 B$, right; $C$ ). Although the occurrence of SWRs during eating was expected, their absence during the goal period seems at odds with previous findings (Foster and Wilson, 2006). A combination of factors might explain the inconsistency. First, contrary to the present study, rats consumed reward at the goal sites in the study by Foster and Wilson (2006). Other factors could contribute to the observed results, however. These include greater variability of navigation paths preceding correct goal entries in the present study compared with the path stereotypy in the linear track in the study by Foster and Wilson (2006), the short duration (2 s) of each goal period, and the rat's extensive experience with the task. An additional factor could be the general state of the rat at the goal, because our protocol involved the rat strongly attending to its spatial location and expecting the release of a food pellet.

Additional support for the idea the rat is in a "navigational state" at the goal despite immobility is provided by analyzing the hippocampal EEG in the theta frequency band $(4-12 \mathrm{~Hz})$. To characterize the occurrence of theta, we examined EEG power during the $2 \mathrm{~s}$ preceding arrival to the goal and the $2 \mathrm{~s}$ goal period. We found that the $2 \mathrm{~s}$ goal periods were associated with a significant drop in power ( $5 \mathrm{~dB}$ on average) $\left(t_{(16)}=5.78 ; p<0.0001\right)$ at the peak theta frequency $(7.77 \pm 0.06 \mathrm{~Hz})$ seen before goal arrival. Theta was not, however, abolished because there was still a strong peak at a slightly lower frequency $(7.37 \pm 0.09 \mathrm{~Hz})$ during the goal period (Fig. $8 D$ ); the difference in peak frequency was highly significant $\left(t_{(16)}=4.98 ; p<0.001\right)$. A more detailed inspection of ERSPs during the $4 \mathrm{~s}$ period preceding activation of the food dispenser revealed a significant change in theta power in only 3 of 17 sessions; in these cases, the perturbation occurred approximately at the middle of the goal period. In the remaining 14 sessions, no perturbation was observed (Fig. 7E). In summary, goal periods were associated with a small power decrease and a small downward shift of the dominant theta frequency. Because it is known that theta frequency increases with running speed (Slawinska and Kasicki, 1998; Maurer et al., 2005), the lower theta in the goal period might thus be attributable to an average slower movement in the goal zone. Another tentative explanation of this pattern of results is that type I (movement-associated) theta occurred before rats arrived at the goal, whereas type II (still alertness) theta occurred as the rat stayed in the goal zone. Considered together, therefore, our EEG results suggest that elevated goal firing is a very different phenomenon than the reverse replay seen during locomotor pauses on an elevated track (Foster and Wilson, 2006). It is especially interesting that the theta rhythm was always present during goal periods.

\section{Interneuron discharge in the place task}

Because the firing rate of interneurons is negatively correlated with running speed (McNaughton et al., 1983), we asked whether 


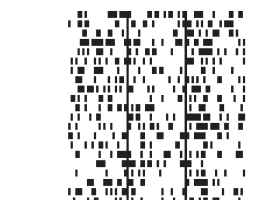

$15 \mathrm{~Hz}$

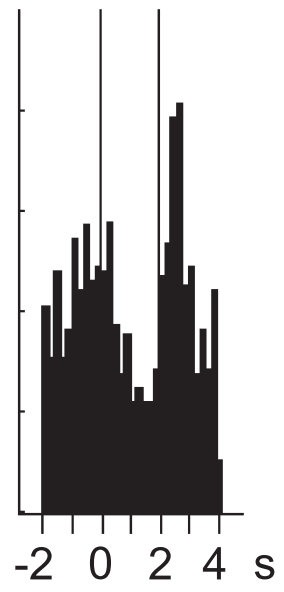

(A)

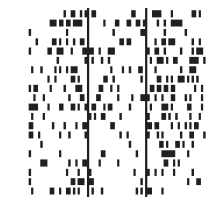

$15 \mathrm{~Hz}$

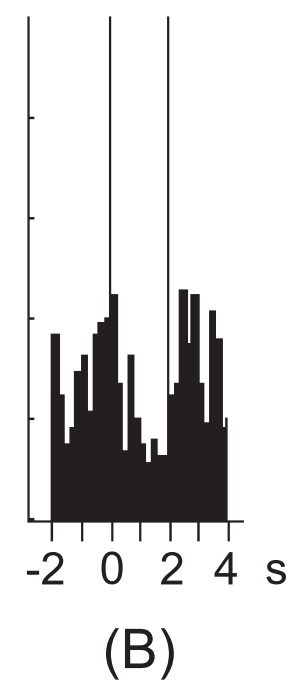

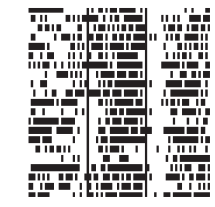

$20 \mathrm{~Hz}$

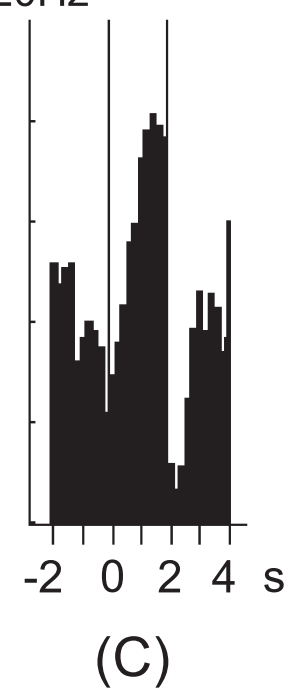

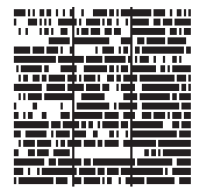

$35 \mathrm{~Hz}$

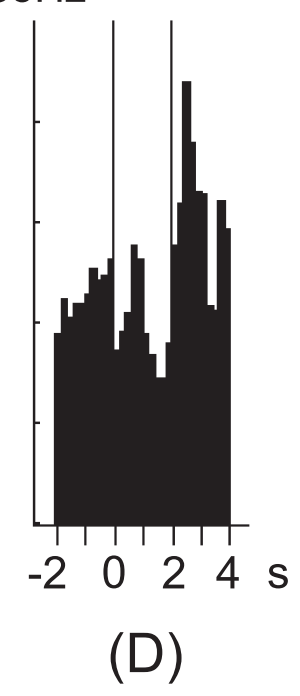

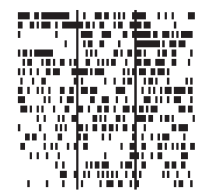

$20 \mathrm{~Hz}$

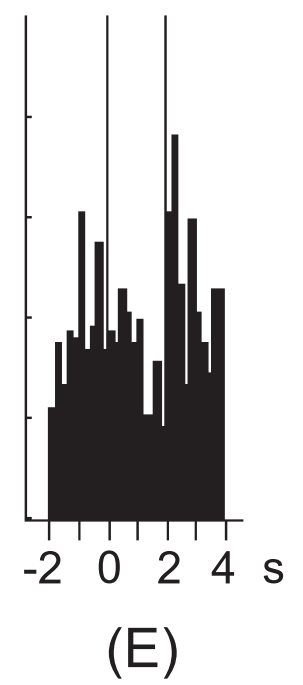

Figure 8. Temporal activity of five example interneurons. Raster plots and PETHs for these putative interneurons are shown in the same way as the place cells in Figures 2 and 3 . The $2 \mathrm{~s}$ goal period $(0-2 \mathrm{~s})$ is bracketed by vertical lines ( $200 \mathrm{~ms}$ bins). Although all interneurons showed marked variations in discharge during the goal period, no consistent across-cell pattern emerged. Cells were seen whose discharge decreased (e.g., cells A and B), increased (e.g., cell C), or had more complicated, multiphasic patterns of change during the goal period (e.g., cells D and E).

excess place cell firing at the goal could result from decreased interneuron activity and consequent disinhibition of pyramidal cell excitatory activity. To assess this simple possibility, we made perievent time histograms of spike activity for a few interneurons recorded in the place task, with $t=0 \mathrm{~s}$ when the rat entered the goal zone and $t=2 \mathrm{~s}$ when the dispenser was activated (for five example PETHs, see Fig. 8). Although some interneurons in fact showed decreased discharge rates during successful pauses at the goal (Fig. 8, cells A and B), others instead showed increased activity at the same time (Fig. 8, cell C), whereas still others showed complicated biphasic or multiphasic activity pattern changes (Fig. 8, cell D). This variety of effects is in line with the diversity of interneuron responses (Jonas et al., 2004) and renders unlikely the simple idea that increased place cell activity at the goal is attributable to a general tendency of all interneurons to decrease activity. We conclude that a proper analysis of the role of interneurons in excess goal firing (and in fact the entire range of place cell-associated phenomena) must await a means of identifying the anatomical identity and therefore the connections of the heterogeneous interneuron population.

\section{Discussion}

The main finding of this study is that place cells recorded during a hidden goal task generally have distinct although weaker secondary firing fields at the goal in addition to their characteristic main firing fields. In agreement with a great deal of early work, the main firing fields are widely distributed over the cylinder surface (Muller et al., 1987). Most of the same cells, however, also fire at a detectably elevated rate in the unmarked region the hungry rat must visit to release a food pellet. Our basic contention is that the usual location-specific firing and the goal-specific firing reported here represent two different firing modes. Locationspecific firing conveys an ongoing signal about the rat's current whereabouts in the environment; goal-specific firing may be an internal signal that a decision about arrival at a critical location is correct.

Previous analyses of firing field distributions in rats during performance of goal-related tasks have yielded inconsistent results. Field accumulation at the goal was seen while rats swam in an annular water maze in which an escape platform could be raised at a fixed location (Hollup et al., 2001), suggesting that the hippocampus overrepresents behaviorally significant regions of space. In a follow-up study, moving the platform to a new location induced excess firing at the new location (Fyhn et al., 2002), but this excess firing vanished rapidly as the rat learned the new goal. These studies may indicate that a fraction of hippocampal place cells encode the match/mismatch relationship between stored and current information about spatial events. Previously, Deadwyler et al. (1996) made a similar proposal based on an analysis of the activity of small populations of hippocampal cells in rats solving a delayed-matching-to-sample task. Finally, Kobayashi et al. (2003) recorded place cells from rats trained to take fixed trajectories to obtain intracranial stimulation rewards at two specific locations in a cylinder. They found that some cells changed their firing patterns as the rat learned the task and displayed excess firing at the two rewarded locations.

In contrast to these reports of excess place cell field numbers at goals, we failed to see any such tendency during performance of the place preference task. This could be a result of dissociating the fixed pellet release zone from the variable reward site whose position depends on the bouncing of a pellet. Note, however, that several studies in which the goal and reward sites were coincident also failed to see firing field accumulation at the goal (Speakman and O'Keefe, 1990; Trullier et al., 1999). It is therefore possible that other tasks properties such as the great importance of goal location in a water maze may reshape the hippocampal representation so that fields overrepresent specific places (Hollup et al., 
2001; Fyhn et al., 2002). It is also possible that field accumulation at a goal may sometimes instead reflect excess goal firing of silent cells or with a field elsewhere in space, as seen here.

The excess goal firing of place cells has several interesting properties. First, it is restricted to pauses long enough to release a food reward and was not seen when the rat passed through the goal zone during foraging. Second, excess goal firing is not a consequence of the tendency of rats to move slowly in the goal region because slow walking elsewhere in the apparatus (away from the main firing field) was not accompanied by elevated firing. Third, we note that excess firing was more intense during the second half of the $2 \mathrm{~s}$ goal period although the running animal's speed was constant over the entire $2 \mathrm{~s}$ goal period. Thus, we conclude that, although the running speed influences place cell activity (McNaughton et al., 1983; Wiener, 1996), it fails to explain excess firing at the goal in the present study.

The delayed firing rate increase after the rat stopped in the goal zone is intriguing. Recently, Hölscher et al. (2003) recorded place cell activity as rats solved two versions of the radial arm maze task; in one version, all eight arms were baited, whereas in the other only four arms were baited. In both versions, the animals were left on the maze after all baited arms were visited. In both versions, many neurons fired more during visits to baited arms than to never-baited arms (four-baited arm version of the task) or in arms visited again after the bait had been retrieved (eight-baited arm version), a result explained in terms of extra attention or reward expectation on baited arms. Overall, our data are consistent with Hölscher et al. (2003), because we saw excess discharge when the rat stops in the goal zone, at a time when it attends to the task and expects a reward. Nevertheless, the temporal pattern of increased discharge at the goal is not what we would expect if increased attention or reward expectation were the only underlying processes; the temporal dynamics of such processes predict a continuous discharge increase during the goal period, whereas we found that discharge reaches a peak after $\sim 1$ $s$ and then sharply declines. Thus, attention or reward expectation may play a part, but other factors may be important or even dominant.

An interesting possibility is that excess goal discharge occurs during the SWR events seen during quiet alertness whose presence may reflect increased hippocampal excitability (Buzsáki, 1986). Hippocampal EEG recordings in three rats revealed, however, that SWRs were mainly confined to putative eating episodes and were rare at other times during the session. In fact, SWRs were hardly ever seen as rat waited for an expected reward to be released, at the time they could account for excess goal firing. In line with the lack of SWRs during goal periods, our analysis of the EEG in the low-frequency range revealed that goal periods were not associated with a cessation of theta activity. We saw instead a decrease in theta frequency suggestive of a shift from type I (movement-related) to type II (still alertness) theta activity (Sainsbury et al., 1987; Vanderwolf, 1988). To our knowledge, such hippocampal state is not associated with increased cell excitability. Another possible explanation of excess goal firing is that it occurs in relation to an undetermined aspect of the rat's behavior when it arrives at the goal zone. We saw, however, that speed profiles were similar in the cue task and the hidden goal place task, although the dynamics for excess goal activity were different. Based on these considerations, we do not believe that the overall behavioral state accounts for excess goal discharge.

The explanation we currently prefer is that increased firing during the goal period provides an internal feedback signal that indicates the rat has reached the right place. There are several possible ways of arranging the excess goal activity to provide such an across-cell signal including the observed tendency for synchronous firing. The statistics of spike trains indicate that the number of nearly coincident spikes is much higher than expected by chance. Even if synchronized states are brief and relatively unreliable for any given pair of neurons, such states may provide a coherent output signal at the population level. Such a signal could serve as a signature of the rat's awareness that it is at the correct location and therefore has reached the right decision (Singer, 2005). In this vein, it is interesting that the proposed signal appears earlier if at a marked goal than if goal location must be calculated. Because the rats' movements appeared essentially the same in both tasks, we speculate that the delay in initiation of goal period firing in the hidden goal task results from the extra computations required for the rat to "convince" itself that it is in the goal. Although only speculations can be offered about their nature, such extra computations could involve on-line maintenance of the memory representation of the goal, specific comparisons of the currently perceived panorama with a memory template of the goal panorama, or even a temporal estimation of the time spent in the goal zone.

In summary, we propose that place cells represent not only the geometry of the current environment but also reflect identification of a goal location, providing on-line feedback about navigational performance. Such goal signals would nicely complement information provided by cells in the medial prefrontal cortex, recently shown to provide coarse encoding of goal location and hypothesized to participate in path planning (Poucet et al., 2000, 2004; Hok et al., 2005). That hippocampal place cells also have a goal signal, albeit quite different in nature, suggests that both structures could participate in a distributed neural network that allows the rat to plan accurate trajectories in space.

\section{References}

Brown EN, Frank LM, Tang D, Quirk MC, Wilson MA (1998) A statistical paradigm for neural spike train decoding applied to position prediction from ensemble firing patterns of rat hippocampal place cells. J Neurosci 18:7411-7425.

Buzsáki G (1986) Hippocampal sharp waves: their origin and significance. Brain Res 398:242-252.

Deadwyler SA, Bunn T, Hampson RE (1996) Hippocampal ensemble activity during spatial delayed-non-match-to-sample performance in rats. J Neurosci 16:354-372.

Delorme A, Makeig S (2004) EEGLAB: an open source toolbox for analysis of single-trial EEG dynamics including independent component analysis. J Neurosci Methods 134:9-21.

Fenton AA, Csizmadia G, Muller RU (2000) Conjoint control of hippocampal place cell firing by two visual stimuli. I. The effects of moving the stimuli on firing field positions. J Gen Physiol 116:191-209.

Foster DJ, Wilson MA (2006) Reverse replay of behavioural sequences in hippocampal place cells during the awake state. Nature 440:680-683.

Friedman HS, Priebe CE (1998) Estimating stimulus response latency. J Neurosci Methods 83:185-194.

Fyhn M, Molden S, Hollup S, Moser MB, Moser EI (2002) Hippocampal neurons responding to first-time dislocation of a target object. Neuron 35:555-566.

Gawne TJ, Kjaer TW, Richmond BJ (1996) Latency: another potential code for feature binding in striate cortex. J Neurophysiol 76:1356-1360.

Gothard KM, Skaggs WE, Moore KM, McNaughton BL (1996) Binding of hippocampal CA1 neural activity to multiple reference frames in a landmark-based navigation task. J Neurosci 16:823-835.

Hok V, Save E, Lenck-Santini PP, Poucet B (2005) Coding for spatial goals in the prelimbic/infralimbic area of the rat frontal cortex. Proc Natl Acad Sci USA 102:4602-4607.

Hollup SA, Molden S, Donnett JG, Moser MB, Moser EI (2001) Accumulation of hippocampal place fields at the goal location in an annular watermaze task. J Neurosci 21:1635-1644. 
Hölscher C, Jacob W, Mallot HA (2003) Reward modulates neuronal activity in the hippocampus of the rat. Behav Brain Res 142:181-191.

Huxter JR, Thorpe CM, Martin GM, Harley CW (2001) Spatial problem solving and hippocampal place cell firing in rats: control by an internal sense of direction carried across environments. Behav Brain Res 123:37-48.

Jeffery KJ, Gilbert A, Burton S, Strudwick A (2003) Preserved performance in a hippocampal-dependent spatial task despite complete place cell remapping. Hippocampus 13:175-189.

Jonas P, Bischofberger J, Fricker D, Miles R (2004) Interneuron diversity series: fast in, fast out-temporal and spatial signal processing in hippocampal interneurons. Trends Neurosci 27:30-40.

Kobayashi T, Tran AH, Nishijo H, Ono T, Matsumoto G (2003) Contribution of hippocampal place cell activity to learning and formation of goaldirected navigation in rats. Neuroscience 117:1025-1035.

Kubie JL (1984) A driveable bundle of microwires for collecting single-unit data from freely moving rats. Physiol Behav 32:115-118.

Lee AK, Wilson MA (2002) Memory of sequential experience in the hippocampus during slow wave sleep. Neuron 36:1183-1194.

Lenck-Santini PP, Save E, Poucet B (2001) Evidence for a relationship between place-cell spatial firing and spatial memory performance. Hippocampus 11:377-390.

Lenck-Santini PP, Muller RU, Save E, Poucet B (2002) Relationships between place cell firing fields and navigational decisions by rats. J Neurosci 22:9035-9047.

Lenck-Santini PP, Rivard B, Muller RU, Poucet B (2005) Study of CA1 place cell activity and exploratory behavior following spatial and nonspatial changes in the environment. Hippocampus 15:356-369.

Makeig S (1993) Auditory event-related dynamics of the EEG spectrum and effects of exposures to tones. Electroencephalogr Clin Neurophysiol 86:283-293.

Maurer AP, Vanrhoads SR, Sutherland GR, Lipa P, McNaughton BL (2005) Self-motion and the origin of differential spatial scaling along the septotemporal axis of the hippocampus. Hippocampus 15:841-852.

McNaughton BL, Barnes CA, O'Keefe J (1983) The contributions of position, direction, and velocity to single unit activity in the hippocampus of freely-moving rats. Exp Brain Res 52:41-49.

Muller RU (1996) A quarter of a century of place cells. Neuron 17:813-822.

Muller RU, Kubie JL, Ranck Jr JB (1987) Spatial firing patterns of hippocampal complex-spike cells in a fixed environment. J Neurosci 7:1935-1950.

O'Keefe J, Dostrovsky J (1971) The hippocampus as a spatial map. Preliminary evidence from unit activity in the freely moving rat. Brain Res 34:171-175.
O'Keefe J, Speakman A (1987) Single unit activity in the rat hippocampus during a spatial memory task. Exp Brain Res 68:1-27.

O’Neill J, Senior T, Csicsvari J (2006) Place-selective firing of CA1 pyramidal cells during sharp wave/ripple network patterns in exploratory behavior. Neuron 49:143-155.

Paxinos G, Watson C (1986) The rat brain in stereotaxic coordinates. New York: Academic.

Poucet B, Save E, Lenck-Santini PP (2000) Sensory and memory properties of hippocampal place cells. Rev Neurosci 11:95-111.

Poucet B, Lenck-Santini PP, Hok V, Save E, Banquet JP, Gaussier P, Muller RU (2004) Spatial navigation and hippocampal place cell firing: the problem of goal encoding. Rev Neurosci 15:89-107.

Rossier J, Kaminsky Y, Schenk F, Bures J (2000) The place preference task: a new tool for studying the relation between behavior and place cell activity in rats. Behav Neurosci 114:273-284.

Sainsbury RS, Heynen A, Montoya CP (1987) Behavioral correlates of hippocampal type 2 theta in the rat. Physiol Behav 39:513-519.

Sakurai Y (1990) Hippocampal cells have behavioral correlates during the performance of an auditory working memory task in the rat. Behav Neurosci 104:253-263.

Sakurai Y (2002) Coding of auditory temporal and pitch information by hippocampal individual cells and cell assemblies in the rat. Neuroscience 115:1153-1163.

Singer W (2005) How does the brain know when it is right? In: Neurobiology of human values (Changeux JP, Damasio AR, Singer W, Christen Y, eds), pp 125-135. Berlin: Springer.

Slawinska U, Kasicki S (1998) The frequency of rat's hippocampal theta rhythm is related to the speed of locomotion. Brain Res 796:327-331.

Speakman A, O’Keefe J (1990) Hippocampal complex spike cells do not change their place fields if the goal is moved within a cue controlled environment. Eur J Neurosci 2:544-555.

Trullier O, Shibata R, Mulder AB, Wiener SI (1999) Hippocampal neuronal position selectively remains fixed to room cues only in rats alternating between place navigation and beacon approach tasks. Eur J Neurosci 11:4381-4388

Vanderwolf CH (1988) Cerebral activity and behavior: control by central cholinergic and serotonergic systems. Int Rev Neurobiol 30:225-340.

Wiener SI (1996) Spatial, behavioral and sensory correlates of hippocampal CA1 complex spike cell activity: implications for information processing functions. Prog Neurobiol 49:335-361.

Wiener SI, Paul CA, Eichenbaum H (1989) Spatial and behavioral correlates of hippocampal neuronal activity. J Neurosci 9:2737-2763.

Wilson MA, McNaughton BL (1993) Dynamics of the hippocampal ensemble code for space. Science 261:1055-1058. 